\title{
Narrativas sobre o processo saúde-doença: experiências em grupos operativos de educação em saúde
}

Cesar Augusto Orazem Favoreto ${ }^{1}$ Cristiane Coelho Cabral $^{2}$

FAVORETO, C.A.O.; CABRAL, C.C. Narratives on the health-disease process: experiences in health education operational groups. Interface - Comunic., Saúde, Educ., v.13, n.28, p.7-18, jan./mar. 2009.

This paper aims to analyze the enlargement of meanings in narratives on the health-disease process among people with chronic diseases who participated in a health education operative group. It points to the narratives based on a experience whose main objective is to foster the collective elaboration of meanings for illness, and to integrate personal experiences and knowledge with biomedical knowledge and clinical practice. Through semi-structured interviews, the work evaluated the construction of meanings on illness beyond the biomedical model, and the impacts of this new narrative on the way the patient lives, at present, his clinical and therapeutic process. We found that people, through interchange, valorization and legitimation of meanings and knowledge arising from individual and collective experiences within the group, change their concepts on the healthdisease process that transcend the medicalizing perspective of biomedicine.

Key words: Narrative medicine. Health education. Chronic diseases.
Pretendeu-se, neste trabalho: analisar a ampliação dos significados nas narrativas sobre o processo saúde-doença em portadores de doenças crônicas que participaram de um grupo operativo de educação em saúde; identificar as narrativas formadas a partir de uma experiência que visa promover a elaboração coletiva de novos significados para o adoecimento e integrar as vivências e saberes pessoais com o conhecimento biomédico e a prática clínica. Por meio de entrevistas semiestruturadas, avaliou-se a construção de significados sobre o adoecimento para além do modelo biomédico e os impactos desta nova narrativa sobre o modo como o paciente vivencia, no presente, seu processo clínico terapêutico. Identificouse que as pessoas, mediante troca, valorização e legitimação de significados e saberes desenvolvidos a partir das vivências individuais e coletivas no grupo, produzem mudanças nas suas concepções sobre o processo saúde-doença que transcendem a perspectiva medicalizante da biomedicina.

Palavras-chave: Medicina narrativa. Educação em Saúde. Doenças crônicas.
${ }^{1}$ Médico. Departamento de Medicina Integral, Familiar e Comunitária, Faculdade de Ciências Médicas, Universidade Estadual do Rio de Janeiro (UERJ). Rua São Francisco Xavier, 649, casa 7, Maracanã, Rio de Janeiro, RJ, Brasil. 20.550-011 cesarfavoreto@globo.com ${ }^{2}$ Médica Residente em Medicina de Família e Comunidade. Departamento de Medicina Integral, Familiar e Comunitária, Faculdade de Ciências Médicas, UERJ. 
A atenção realizada pelos médicos em uma prática clínica centrada apenas na racionalidade biomédica não tem demonstrado efetividade, sobretudo no que tange à atenção aos portadores de doenças crônicas (Bury, 2001). Neste sentido, as intervenções tradicionais na clínica, como o diagnóstico realizado com base em uma anamnese restrita à coleta de sinais e sintomas das doenças e sob uma perspectiva da terapêutica restrita à prescrição de fármacos, têm dificultado a compreensão dos problemas e significados envolvidos no processo de adoecimento, assim como a adesão dos pacientes aos programas terapêuticos oferecidos (Favoreto, 2004; Camargo Jr., 1997).

$\mathrm{Na}$ atenção aos portadores de doenças crônicas, o modelo de prática clínica centrado na dimensão biomédica e com olhar dirigido apenas para a doença se torna ainda menos eficiente do que em situações nas quais ocorrem formas de adoecimento agudo (Bury, 2001). Para maior efetividade da atenção aos portadores de doenças crônicas, torna-se fundamental que a prática clínica assuma uma dimensão dialógica, interativa e cuidadora (Kleinman, 1988).

A vivência das pessoas com formas crônicas de adoecer e de sofrer exige que o médico entenda o significado de todo o adoecimento e atue integrando o saber médico com o do paciente, produzindo uma síntese que o inclui como sujeito no processo clínico-terapêutico. Do contrário, como Júlio de Mello afirma, o paciente se torna dependente dos remédios ou do médico (Mello Filho, 2000).

As noções de sujeito e de intersubjetividade passam a ser centrais quando se pensa uma clínica que avance em uma perspectiva mais dialógica e cuidadora para as pessoas (Ayres, 2001). Essa dialogicidade facilita o surgimento das dificuldades subjacentes à adesão ao tratamento e promove um novo entendimento do papel da terapêutica, que pode conduzir à ação e à transformação das pessoas envolvidas. Com essa perspectiva, fomentam-se novas iniciativas para a resolução das dificuldades e a produção de novas narrativas, capazes de transformar informação em atitude e que impliquem que os homens assumam seu papel de sujeitos que fazem e refazem o mundo (Silveira, Ribeiro, 2004).

No sentido de revalorizar o papel dos portadores de doenças crônico-degenerativas como sujeitos, e compreender os significados por eles produzidos sobre o processo de saúde e adoecimento e as intervenções clínico-terapêuticas, utilizaram-se, como referencial conceitual e metodológico: a abordagem e análise da narrativa.

Parte-se do reconhecimento da narrativa como um elemento para a compreensão: dos textos e dos contextos mais amplos, diferenciados e mais complexos; da experiência das pessoas e o modo específico como elas fazem a construção e constituição de suas vivências. Assim, a narrativa representa, ao mesmo tempo, modelos do mundo e modelos do self, pelos quais construímos a nós mesmos como parte de nosso mundo (Brockmeier, Harré, 2003).

Para Bakhtin (2004), as palavras e as formas de comunicá-las permitem trazer à tona o mundo interior, isto é, expressar os significados produzidos pela consciência individual e construídos no contexto social no qual o indivíduo se realiza como pessoa. Deste modo, a palavra e a enunciação por ela expressa teriam o papel de materializar a vida semiótica interior.

A narratividade, ao integrar o contexto de vida das pessoas e a construção de suas realidades e identidades, é compreendida por Hydén (1997) como fruto de uma síntese de discursos políticos e morais, criados pelas pessoas para entenderem e julgarem as circunstâncias e situações em que vivem. A importância da narrativa para o indivíduo estaria, assim, nas possibilidades que ela cria de percebermos, vivenciarmos e julgarmos nossas ações e o curso de nossas vidas (Donald, 2002).

A narrativa e sua análise representam, portanto, uma ferramenta conceitual e operativa, que permite evidenciar as ligações entre a identidade da pessoa, sua experiência do adoecimento e a cultura a que ela pertence e em que está envolvida (Bury, 2001). Ao incorporar e ordenar os eventos, subjetiva e cronologicamente, a narrativa pessoal do adoecimento produz um enredo que integra causa e efeito com as variáveis do caráter humano e da motivação pessoal (Hunter, 1996).

Neste sentido, a narrativa pode ser vista como um "conceito operativo central" para a abordagem e compreensão da identidade das pessoas adoecidas (Hydén, 1997). Kleinman (1988) esmiúça esta idéia, e considera a narrativa uma ferramenta de análise que se destina a identificar como os pacientes dão forma e voz a seus sofrimentos de modo diferente de como a biomedicina os representa.

Por outro lado, a análise da narrativa do adoecimento incorpora, de modo significativo, o papel dos fatores situacionais na construção dos significados pessoais do processo saúde-doença. Investigam-se as 
imponderáveis possibilidades de construção de novas narrativas em cada novo contexto, particularmente a cada interação entre o narrador e o ouvinte, e vice-versa. Esta inflexão tem possibilitado estudar a experiência de adoecimento do paciente, e o mundo no qual ele está inserido, como uma realidade social e cultural (Greenhaulgh, 2002; Hydén, 1997; Good, Good, Delveccchio, 1981).

A valorização e compreensão da narrativa, pelos profissionais de saúde, podem, assim, ampliar a capacidade de escutar e interpretar as falas e demandas dos pacientes para além dos sinais e sintomas expostos no encontro clínico, e, por conseguinte, facilitar o entendimento do significado das histórias dos pacientes (Greenhaulgh, 2002; Charon, 2001). A falta desta percepção pode interferir negativamente na efetividade das ações terapêuticas, e explicar, em muitos casos, a falta de adesão a elas. Nesta situação, a baixa adesão pode ser diretamente influenciada pela forma como as pessoas vivenciam e concebem seu adoecimento e pelas intervenções propostas pelos profissionais de saúde.

Por outro lado, o desenvolvimento da narrativa no processo clínico-terapêutico, como na psicanálise, pode adquirir papel terapêutico central. Ao achar as palavras capazes de expressar as desordens e os medos delas decorrentes, a pessoa dá forma e exerce controle sobre o caos e as rupturas provocadas pela enfermidade (Charon, 2004; Frank, 1995).

Ressaltar a importância terapêutica da narrativa representa entender o paciente como personagem de seu próprio adoecer e que, como sujeito, interage com outros saberes e poderes; defende seus argumentos, negocia responsabilidades, define identidades e pleiteia direito a um determinado saber.

Neste caso, os novos repertórios e atitudes podem ter impacto sobre o projeto terapêutico em aspectos que transcendem a simples adesão aos fármacos (Frank, 1995). Podem influir na superação de rupturas produzidas pelo adoecimento, na formação de uma nova identidade cultural e social e, sobretudo, na produção da autonomia e melhoria da qualidade de vida.

Partindo deste entendimento, tomaram-se, como objeto de estudo, as narrativas construídas sobre o processo saúde-doença e clínico-terapêutico desenvolvidas por portadores de doenças crônicas, após participarem de um grupo operativo de educação em saúde.

Os objetivos da pesquisa foram: observar se as pessoas, com base em uma vivência dialógica e coletiva, ampliam os significados do processo saúde-doença para além de uma concepção biomédica; e como esses novos sentidos são incorporados em suas narrativas pessoais sobre o adoecimento.

\section{As características do grupo ConViver}

Este grupo, que funciona há sete anos, é formado por portadores de doenças crônico-degenerativas, como: diabetes mellitus tipo II, hipertensão arterial sistêmica e/ou obesidade. Os pacientes são convidados, pelos médicos residentes e internos dos ambulatórios do Hospital Universitário Pedro Ernesto (HUPE - UERJ), a participarem desta atividade.

O Grupo ConViver é organizado na forma de grupo fechado de participantes, com encontros semanais, de duas horas de duração, ao longo de três meses. Esses encontros são coordenados por residentes do segundo ano de Medicina de Família e Comunidade e psicólogos do Curso de Especialização em Psicologia Médica da FCM/UERJ, sob supervisão docente.

Silveira (2004, p.95) descreve esse grupo de adesão como "operativo e terapêutico, tendo em vista que seu objetivo é identificar dificuldades, discutir possibilidades e encontrar soluções adequadas para problemáticas que estejam dificultando o tratamento". Assim, o grupo operativo se propõe a ser informativo, reflexivo e de suporte, objetivando o desenvolvimento da autonomia dos pacientes.

Com base na complexidade e na integralidade da saúde, o grupo desenvolve, coletivamente, temas trazidos pelos participantes, que envolvem aspectos da saúde, doença e da vida, como: religiosidade, sexualidade, morte, remédios, efeitos colaterais, automedicação, regimes terapêuticos, preconceitos, política, violência, tristezas, alegrias - uma multiplicidade de temas que ilustra a amplitude na qual está inserida a adesão ao tratamento (Silveira, 2004). 


\section{Estratégia da pesquisa}

Para se aproximar dos significados do adoecimento construídos pelas pessoas com base em suas experiências no ConViver, foram aplicadas 15 entrevistas semiestruturadas, realizadas com um número proporcional e uma amostra aleatória entre os 62 participantes dos seis grupos realizados em 2006. A pesquisa foi aprovada pelo Comitê de Ética em Pesquisa do HUPE-UERJ.

As entrevistas foram aplicadas após o consentimento informado dos pacientes, gravadas em meio digital e, em seguida, transcritas e analisadas por dois pesquisadores. As questões norteadoras das entrevistas foram relativas à vivência, às percepções e ao significado pessoal do adoecimento, desenvolvido com base na participação no grupo.

É importante observar que as pessoas entrevistadas não representam a clientela geral do ambulatório. A participação nesse grupo de convivência e educação em saúde, por si só, significa uma seleção desta clientela em relação à população geral do ambulatório. Essas pessoas chegaram ao grupo, em sua maioria, a partir da orientação de seus médicos acompanhantes. Neste caso, segundo as falas dos pacientes e a experiência acumulada com esta atividade nos últimos sete anos, o vínculo criado na relação médico-paciente nas consultas havia sido o principal fator motivador para a participação no grupo.

O vínculo com os médicos assistentes se refletia nos relatos sobre a boa adesão aos tratamentos farmacológicos preconizados, assim como na maior informação dos pacientes quanto às condutas terapêuticas que envolvem o processo de adoecimento.

As falas dos entrevistados não expunham ruídos relacionados ao vínculo entre médico e paciente ou a problemas com a adesão aos medicamentos. Não é possível descartar a possibilidade de que o fato de o entrevistador ser médico - e, assim, ser identificado com a instituição onde os pacientes são atendidos - possa ter influenciado o rumo das falas dos pacientes. Contudo, este enfoque dado pelos pacientes a suas narrativas facilitou dirigir o foco e a análise das entrevistas para a formação das concepções pessoais sobre o processo saúde-doença e cuidado.

O contexto e a forma como a pesquisa se desenvolveu permitiram que a análise do material pudesse centrar-se na identificação da formação de narrativas sobre o adoecer e o viver com a doença crônica/ tratamento, buscando aspectos que transcendessem a concepção e definição do adoecimento e da adesão, como é formulada na racionalidade biomédica.

Esta apreciação, portanto, afastou-se de uma idéia simplista e mecânica de avaliação e quantificação da adesão ao tratamento farmacológico, como também não pretendeu avaliar as estratégias metodológicas aplicadas no ConViver. Manteve-se o foco nos aspectos narrativos envolvidos na construção de uma forma mais integral de: perceber o adoecimento, desenvolver a autonomia e participar do processo saúde-doença e cuidado.

Para viabilizar essa avaliação, os principais sentidos expressos sobre o processo saúde-adoecimento e clínico-terapêutico das narrativas das pessoas foram condensados em três categorias de análise:

- a construção de significados sobre o adoecer que transcendem a visão biomédica de saúde e doença;

- a narrativa sobre o modo como o paciente vivencia o processo clínico-terapêutico;

- a integração dialógica entre os contextos culturais e o processo de saúde-doença e cuidado.

Cabe destacar que estas categorias analíticas surgiram com base nos objetivos definidos pelos autores e nas próprias questões emergentes das falas dos entrevistados. Portanto, são categorias oriundas do próprio material empírico, e não uma forma de ajustamento da realidade. Foram um meio de organizar os diferentes aspectos das falas na forma de um texto que melhor traduzisse as experiências pessoais. 


\section{Discussão dos resultados}

\section{A construção de significados sobre o adoecimento que transcendem a visão biomédica da doença}

A construção de novos repertórios interpretativos e explicativos sobre o adoecer foi percebida nas falas dos pacientes entrevistados. Eles expuseram que, a partir da oportunidade dialógica vivenciada no grupo, começaram a fazer relações de seus sinais e sintomas (e as variações de parâmetros biomédicos, como a pressão arterial) com os aspectos da vida que os mobilizavam, causavam apreensão, angústia e/ ou tristeza.
Agora meu filho (portador de Alzheimer) está mais calmo, apesar de ainda estar desmemoriado. Assim eu fui me acalmando e a pressão controlou. Eu entendi que é um problema que vai e vem, quando ele fica nervoso eu também fico, porque ele telefona muito para mim. Agora eu estou melhorando, estou mais calma. Com as reuniões que nós tivemos nessa sala eu me senti muito bem, o grupo era muito bom, eu comecei a falar mais do que falava antes. (Entrevistada 3)

A construção de novas narrativas sobre o adoecimento, capazes de integrar as sensações e os sentimentos percebidos com as explicações médicas do adoecer, parece que foi se tornando possível por meio do compartilhamento de saberes entre os pacientes do grupo e destes com os profissionais de saúde. Nesses encontros dialógicos, as pessoas reconheciam que trocar experiências boas e ruins relacionadas à vida e ao adoecer, com outros participantes com os quais se identificavam - pela idade, nível socioeconômico, cultura, doença, serviço de saúde que frequentavam ou pelo lugar da cadeira que ocupavam no grupo - os ajudava a entender suas próprias questões.

Quando se percebem sendo capazes de explicar e interpretar os problemas trazidos por outros, as pessoas passam a valorizar sua própria experiência de vida e saberes práticos e dialógicos que desenvolveram, mas que são menosprezados pelo saber médico-científico sobre a doença.

Por outro lado, esse espaço dialógico e de construção de novas narrativas sobre o adoecer foi possível pelo encontro entre o saber técnico (representado pelos profissionais) e o saber prático (dos pacientes e profissionais). Um encontro no qual, a partir da escuta ativa, os profissionais se dispunham a valorizar aspectos do adoecer, como: sofrimento, dúvidas em relação ao tratamento, falta de perspectivas e limitações trazidas pela doença.

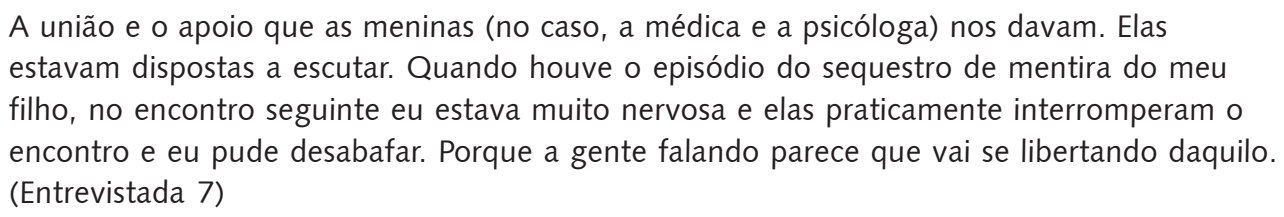

Quando esses aspectos são valorizados e discutidos, entra em cena a vida cotidiana, isto é, uma perspectiva que transcende limites instituídos pelo saber e pelo discurso médico baseado apenas na doença, possibilitando a construção de novos significados para os sujeitos que se encontram adoecidos.

As informações sobre a doença passam a ocupar outro lugar no modo de pensar dos participantes. Conhecer e lidar com os dados biomédicos passa a representar um aspecto de construção de novos significados e de ampliação da autonomia. As informações médicas deixam de ser regras externas ao modo de levar a vida, deixam de significar uma limitação a mais àquelas provocadas pelo medo e o sofrimento que o adoecer trouxe para cada pessoa em particular.

Muitas vezes, essas informações já haviam sido comentadas pelo médico na consulta, mas não traziam este sentido naquele momento. Talvez porque eram ditas por um profissional desconectado das situações cotidianas, cuja abordagem está distante da pessoa adoecida, e as formas de comunicação usam códigos de linguagem que são estranhos e os distanciam dos pacientes no encontro clínico. 
Agora eu procuro ler e o grupo serviu para isso: para poder me orientar. Eu fui ver a pressão: máxima, mínima. Agora eu sei o que é sistólica e diastólica. Para mim foi ótimo passar pelo grupo. Sempre é bom aprender. (Entrevistado 1)

Tem coisas na diabetes que eu não havia entendido. Agora entendo mais. Eu precisava disso para ter mais cuidado com a diabetes como agora eu tenho. Tenho mais atenção com a minha doença, tenho mais cuidado com ela do que eu tinha antes. (Entrevistada 4) Esse grupo era para eu ter mais conhecimento da diabetes e realmente, porque eu não sabia o que eu fazia e agora eu tenho conhecimento de tudo que eu faço. Eu mesmo comia muita gordura, orelha de porco [...]. Parei porque através do grupo a gente vai aprendendo a conviver. (Entrevistado 12)

Mais conhecimento. Saber como resolver; mais confiante. Até para discutir com o médico. (Entrevistada 8)

Outro elemento que está envolvido na construção de novas narrativas seria a possibilidade de se valorizarem os aspectos que envolvem o sofrimento e a subjetividade, na mesma intensidade como são abordadas as questões ligadas à doença e às estratégias de tratamento. "Talvez, se eu não tivesse esse problema do meu filho dependente, talvez não me interessaria. Mas como eu tenho essa barra dentro de casa, acho que para mim é muito importante ter esse suporte" (Entrevistado 1); "Fui para o grupo porque eu ficava chorando. Antes sentia mais coisas, agora estou começando a me valorizar mais um pouco, com mais auto-estima" (Entrevistada 14).

Este processo produz um sentimento de acolhimento e uma percepção concreta de integração entre o adoecer, a subjetividade e os aspectos da vida que contribuem para direcionar a narrativa a uma nova forma de compreender o corpo, suas manifestações e seu comportamento.

O diálogo e o acolhimento da experiência de sofrimento permitem que a narrativa do adoecimento se amplie de um tempo presente, para se conectar e explicar o passado e projetar novas formas de lidar com o futuro. A formação de uma nova dimensão temporal na narrativa do adoecimento parece potencializar a projeção do futuro e induzir novas perspectivas para a superação de limitações do presente.

No momento em que participam do grupo, as pessoas o percebem como um lugar de escuta de questões que, apesar de comporem suas histórias e seu sofrimento, não encontram espaço dentro do paradigma biomédico que dirige a consulta médica.

O diálogo entre sujeitos possibilita a formação de uma rede de solidariedade que amplia e valoriza as dimensões da vida onde o adoecimento se institui. Uma rede de apoio que produz uma narrativa que torna o adoecer e o cuidado terapêutico partes da própria vida e cultura, e não apenas uma limitação.

A convivência neste espaço que promove a formação e uma rede de solidariedade e apoio favorece a transformação de experiências pessoais em experiências coletivas. Contribui no sentido de coletivizar a experiência de adoecimento, ao construir uma identidade coletiva que localiza a situação pessoal como parte de uma narrativa e de um contexto político e social mais amplo.

Antes do grupo eu vivia isolada. Eu moro sozinha, não tem ninguém na minha casa, sou eu sozinha. Então o grupo para mim foi muito bom. (Entrevistada 3)

Pensei: se eu tenho problema eu tenho que cuidar dele e não piorar. Então, eu não podia me encher de doces, me encher de comida do jeito que eu estava. Eu tinha que melhorar. Comecei a escutar as pessoas do meu lado, comecei a falar também. Comecei a desabafar, falei muito dos meus problemas, porque eu tenho realmente muitos problemas. Quem não tem? (Entrevistada 4)

Conhecer outras pessoas, fazer amizades. Formei um grupo de amigas. Amizade, porque eu não tinha mais amizade. (Entrevistada 2) 
Esta legitimação social da pessoa adoecida se forma com a oportunidade de compartilhar e se solidarizar com outros, e possibilita a formação de narrativas nas quais o significado do adoecer não se restrinja ao de um castigo, uma ameaça, um fardo a ser solitariamente suportado. "Tem que aprender a conviver. Eu vi que nem só eu tenho isso, outros tem outros problemas. Aí você vê a forma como as pessoas vão levando. Isso é uma experiência pra gente lidar no dia-a-dia" (Entrevistado 1); "Foi legal, fiz amizades. Eu acho que estou um pouco mais calmo também por entender mais sobre a doença. Conviver com os problemas dos outros também; ver que não só eu tenho problemas" (Entrevistado 1).

\title{
Narrativa sobre o modo como o paciente vivencia o processo clínico-terapêutico
}

No processo dialógico do grupo, as informações sobre o adoecer são discutidas a partir das experiências, das formas de linguagem e significados trazidos pelos participantes. Os dados biomédicos são abordados em meio à discussão sobre as dúvidas, as crenças, os medos e as experiências assistenciais vividas pelas pessoas.

A proximidade e a identidade criadas produzem transformações na fala, na atitude e no significado de vida do paciente, que deixa de ser um papel em branco, um ser à disposição das intervenções preconizadas pela medicina, para se tornar sujeito de seu processo saúde-doença-cuidado. Sujeito com uma maior autonomia, capaz de questionar seu médico, pela melhor compreensão sobre o que faz bem ou mal para sua saúde, e com possibilidade de formar um projeto de felicidade próprio, delineado por ele, e não pelo profissional de saúde.

Como referido anteriormente, os pacientes entrevistados relataram uma boa adesão ao tratamento farmacológico. Contudo, em relação à incorporação de hábitos de vida que favorecem a prevenção de novos agravos e a promoção da saúde, eles demonstraram maior dificuldade de adesão.

\begin{abstract}
Não tenho dificuldades. Minha pressão está controlada. O problema é atividade física, a constância. Estou tentando agora fazer a caminhada. Quando eu volto da casa da minha mãe já volto caminhando. Dieta eu já tinha me conscientizado, mas exercício físico ficou mais consciente. Eu agora sei que tenho que fazer. (Entrevistada 8)
\end{abstract}

A dieta, não conseguia fazer no inicio, mas os remédios eu tomava direito. Me sinto muito bem com os remédios. (Entrevistada 4)

Suas falas demonstram que reconhecem a importância de mudanças de estilos de vida, mas também percebem as barreiras sociais, culturais e subjetivas para incorporar novas ações em seu cotidiano.

Além deste reconhecimento, as narrativas apontaram para uma concepção de saúde que integra os elementos da subjetividade e da organização social e cultural à adoção de comportamentos mais saudáveis. Os entrevistados, frequentemente, fazem uma integração entre saúde, qualidade de vida e autoestima. Pode-se identificar, nas falas, um significado amplo para a concepção de saúde, que incorpora perspectivas - como a de bem-estar, autoestima, lazer, atividade física e bom humor - ao processo saúde-doença-cuidado. "Sei que apesar da minha gordura, porque eu estou gorda ainda, saio na rua e tem gente que ainda olha pra mim. [...] Não estou mais arrasada e decepcionada não. Tomo meu banho, me arrumo e saio bonitinha e vou passear. Ainda não sou quem era antes, mas estou caminhando" (Entrevistada 4); "Tento fazer as coisas que vão ser boas pra mim, que me dão prazer. Eu sei que a diabetes, se eu fizer minha dieta legal, se eu me cuidar também da parte emocional eu vou ter uma vida com qualidade por mais tempo" (Entrevistada 15).

As narrativas demonstraram que as pessoas incorporavam orientações - como a prática de exercícios e as mudanças de hábitos alimentares - a uma perspectiva mais ampla de vida e saúde. Estas questões passam a ser mais próximas da identidade e do cotidiano de cada um, e contribuem para uma maior autonomia para eles adequarem as orientações médicas às suas condições e limitações.

A vivência no grupo também parece ter permitido que as pessoas reconhecessem as limitações vividas pelos outros do grupo, assim como as estratégias de adaptação por eles adotadas para aderir às 
necessárias mudanças de comportamento. Desta forma, as trocas de vivências ajudam as pessoas a se capacitarem para gerir suas ações e ampliarem a autonomia sobre o modo de cuidar de sua saúde.

O mais importante foi sobre os alimentos. Isso é muito importante porque a gente tem que saber se policiar, o que a gente come, o que a gente bebe. Saúde é uma coisa muito boa. Então, através desse grupo eu me conscientizei de muita coisa e a gente faz o que aprende e com a tendência de ir melhorando. (Entrevistada 12)

Então, eu chorava muito, não vou te dizer que estou tranquila, mas aceito mais. Porque eu era de pegar esses biscoitos recheados de morango e devorar vendo televisão. Bombom, goiabada no pão, tudo isso foi retirado. (Entrevistada 14)

As narrativas das pessoas trazem um enredo que não fica limitado a cumprir passivamente o papel atribuído ao paciente, de tomar remédios, comparecer a consultas e/ou fazer exames de rotina. A forma e o sentido de suas falas se aproximam de uma abordagem integral, e o paciente se vê como sujeito da promoção de sua saúde.

As narrativas, portanto, sinalizam a possibilidade de transformar o significado de saúde e doença e de buscar novos hábitos de vida que promovam seu bem-estar. São narrativas que ressignificam o sofrimento e a forma de lidar com ele, e que podem representar um ganho em relação a questões objetivas, como a redução do peso, da pressão arterial, da glicemia e de tantas outras referências usadas pela medicina, sem que isso signifique maiores perdas e rupturas ao modo de levar a vida.

\section{A integração dialógica entre os contextos culturais e o processo saúde-doença e cuidado}

Como apresentado no texto, a possibilidade de diálogo e reflexão no grupo criava e expunha novos significados na interface entre o saber médico e as crenças pessoais. A convergência de elementos como as instituições sociais, crenças, cultura, padrões sociais e religiosos - forma narrativas que se caracterizam por sincretismos, isto é, pela integração dos contextos e vivências pessoais com as concepções sobre o processo de saúde-doença e cuidado.

No modo de pensar das pessoas, esses elementos não se organizam na forma de algoritmos. $O$ sincretismo presente nas narrativas forma-se não como a soma de vários fatores, tampouco expressa um processo linear de determinação ou de causalidade; contudo, o arranjo e a perspectiva para integrar esses elementos narrativos são singulares. A especificidade do arranjo desses elementos narrativos pode estar presente: na atribuição de causalidade, na forma de expressar ou justificar a dificuldade de controlar as doenças, na vontade de aderir às propostas terapêuticas e melhorar as condições de saúde, ou na intenção de dar sentido a uma nova identidade pessoal construída a partir do adoecimento.

A família e a religião são exemplos de elementos da vida social e cultural que influenciam quase todas as narrativas. Eles são incorporados como fatores explicativos ou de codeterminação no discurso pessoal quanto ao adoecimento e o cuidado.

O repertório interpretativo dos pacientes em relação ao adoecimento é influenciado pelas estórias e experiências vividas em família. A construção dos significados acompanhava, portanto, as tradições culturais presentes na história familiar que, por sua vez, influíam nas expectativas em relação ao cuidado. Como exemplo, percebe-se uma aceitação maior das situações de adoecimento e de tratamento entre as pessoas que tinham conhecimento e vivência de casos semelhantes na família.

O diabetes eu fazia exames desde novo, eu já esperava um dia aparecer, porque minha mãe quando eu nasci ela já estava com diabetes. (Entrevistado 1)

Minha avó morreu com diabetes naquela época que o tratamento era mais difícil, então eu sempre tive uma noção que o neto poderia ficar também [...]. Mas nunca fiquei assustada. 
Tratei como se já estivesse até esperando porque quase toda minha família é diabética.

(Entrevistada 8)

Para ser sincera à senhora eu acho que não senti nada. Não levei a sério. Não acreditei. Não entrou na minha cabeça que eu estivesse diabética. [...]. Porque minha família é uma família cancerosa. Eu tava esperando o médico dizer que estava com câncer. Se o médico tivesse dito que eu estava cancerosa, eu acho que eu tinha levado mais a sério. (Entrevistada 4)

A modificação inesperada da estrutura familiar, seja por perda, dependência ou chegada de um novo membro, muitas vezes é associada ao aparecimento do adoecimento ou à dificuldade de conseguir controlá-lo. Esses fatos também podem criar marcos subjetivos que se tornam referência na construção temporal das narrativas. "Quando meu marido ficou doente, comecei a emagrecer. Há oito anos ele está paralítico e foi um "baque" para mim. Minha vida mudou completamente, de situação boa (economicamente) passou para ruim. Aí comecei a ficar nervosa, com dor na coluna" (Entrevistada 11); "A minha mudança para a casa do meu filho mudou muito a minha vida. Morava no meu apartamento [...] Então, eu acho que a mudança fez diferença. Eu passei a dormir na sala, no sofá, não tinha meu quarto. Acho que tudo isso influenciou" (Entrevistada 13); "Eu entendi que teria que tomar remédio pela vida inteira. Fiquei muito chateada, porque eu não tomava remédio e não tinha nada até meu marido falecer" (Entrevistada 10).

A narrativa sobre o controle da doença por vezes é construída a partir da presença de situações ou pessoas que trazem novos significados à vida ou a partir da necessidade objetiva de assumir novos papéis sociais e familiares.

Aceito (o infarto do miocárdio) com tranquilidade. Não sei se porque meus filhos precisam ainda muito de mim, apesar do caçula ter 25 anos, ainda é solteiro. [...] Então, não sei se com isso eu aceito tudo e faço tudo certinho. (Entrevistada 7)

Eu vou te dizer uma coisa, graças a Deus eu tenho uma família bem estruturada. Digo, marido. Eu tenho só um filho que vai fazer 40 anos, mas esse meu problema (depressão) pegou ele na adolescência. Mas o meu marido soube conduzir muito bem. Ele sempre me apoiou muito. Acho que foi por isso que estou de pé. (Entrevistada 14)

A participação no grupo e a rede social que ele promove pareciam influir, por si mesmas, na formação de novas sínteses entre o adoecimento, a afetividade e os valores sociais e morais compartilhados. As novas narrativas trazem a incorporação de novas identidades pessoais e sociais construídas no interior do grupo e, a partir dele, com o mundo exterior. Esses novos papéis e identidades se formavam por meio da relação de afeto e apoio que as pessoas vivenciavam, como também pelo encontro de novos sentidos para: a doença, o remédio ou, mesmo, o cuidado dos profissionais de saúde.

Foi bom porque estava há pouco tempo aqui (morando em Vila Isabel) e fiz mais amizades. Até sem conhecer meu marido, as pessoas perguntam se ele está bem, se eu estou bem. Isso é importante. (Entrevistada 11)

Antes do grupo eu vivia isolada. Então o grupo para mim foi muito bom. O mais importante foi a amizade. Nós não deixamos de nos falar [...]. Para mim foi bom porque eu botei para fora muita coisa que eu não falava para ninguém e no grupo todo mundo foi se abrindo, conversando e eu comecei a conversar também. (Entrevistada 3)

Encontrei um apoio. Porque na família eu não tenho em quem recorrer. Meu irmão mais novo é rapaz, então tenho que arrumar uma pessoa para conversar. (Entrevistada 2) 
O modo como as pessoas vivenciam, no grupo, a construção dessa rede de apoio, a partir do diálogo e do seu uso como instrumento de reflexão e de cuidado, pode interagir nas percepções e ações das pessoas em suas próprias relações familiares. Contribui para formar outro modo de interagir consigo e com os outros, ao integrar novas perspectivas e sentidos para o cuidado de si e da família.

\begin{abstract}
Tenho um sobrinho de quinze anos que está viciado em drogas desde os 13. A gente tenta tirar ele dessa vida, mas não consegue. Nunca chego perto dele brigando, xingando. [...] Então, eu vi que não podia guardar todas aquelas coisas para mim. Eu precisava falar com alguém. Agora eu o encaro já de outro jeito. Mas antes eu tinha medo de chegar perto para falar com ele. Agora não. Nunca tratei ele mal, sempre tratei ele com carinho. Mas agora eu sei como conversar com ele. (Entrevistada 4)
\end{abstract}

Tanto é que eu era um pouco agressivo, mas eu também fazia muita coisa que, com o grupo, com palestras, com os amigos do grupo, a gente começa a entender que os problemas não ocorrem apenas nas nossas vidas. (Entrevistada 12)

\begin{abstract}
Valeu muito a pena, porque eu me dou com a vizinhança toda, mas não sou pessoa de ficar conversando na porta. Eu fui criada nesse sistema, meu pai não aceitava nenhum de nós ficar na porta conversando. [...]. Mas agora eu já procuro as pessoas. Eu me sentia muito sozinha, porque meus filhos saem de manhã e voltam só à noite. Eu deixava a televisão ligada o dia inteiro para não me sentir sozinha em casa. Agora eu já não tenho esse problema. Já tem horas que eu desligo a televisão para ficar um pouco em silêncio. (Entrevistada 7)
\end{abstract}

A vivência no grupo parece ter sido capaz de abrir espaços dialógicos e de reflexão que contribuíram para as pessoas integrarem os aspectos sociais e culturais de suas vidas com questões morais (culpa, preconceito, autoestima, expectativa por ajuda etc.) advindas da situação do adoecimento. Na maioria das falas, essa integração parece ter sido capaz de formar gêneros narrativos que ampliam a autonomia e a possibilidade de as pessoas se moverem em direção a objetivos que são por elas valorizáveis e, ao mesmo tempo, socialmente includentes.

\title{
Conclusão
}

O investimento no desenvolvimento de grupos dialógicos para portadores de doenças crônicas mostrou sua importância não apenas devido à necessidade de se ampliar a adesão aos tratamentos farmacológicos. O trabalho identificou que esses grupos, por meio da troca, valorização e legitimação de significados e saberes desenvolvidos a partir das vivências pessoais e coletivas, podem contribuir em mudanças nas concepções sobre o processo saúde-doença entre seus participantes.

As possibilidades criadas pelo diálogo e compartilhamento de significados e saberes em relação à vida, aos sentimentos e aos valores atribuídos ao processo de adoecer possibilitam a formação de novas construções narrativas sobre o adoecimento e a vida com a doença ou a despeito dela. Permitem a inclusão desses saberes e significados num processo explicativo mais amplo que o oferecido pela prática biomédica desenvolvida nas relações entre médico e paciente na clínica. As novas explicações sobre o adoecer, que emergem desse processo dialógico, compreendem o desenvolvimento de narrativas e atitudes que aumentam a autonomia frente à doença e às estratégias terapêuticas. Produzem um sentimento de acolhimento e uma percepção concreta de integração entre o adoecer, a subjetividade e os aspectos da vida que contribuem para direcionar a narrativa para uma nova forma de compreender o corpo, suas manifestações e seu comportamento.

Os elementos apropriados pelas pessoas e o modo de operá-los nas novas construções narrativas são heterogêneos. Os produtos dessas construções são singulares, mas guardam relação com os contextos e expectativas precedentes à participação nos grupos, como as experiências familiares e religiosas com situações de adoecimento. 
Um aspecto central e comum às falas dos participantes dos grupos está relacionado à própria forma como as narrativas são construídas, isto é, a compreensão de que é possível elaborar novas visões pessoais a partir da troca de experiências e saberes com os outros.

Este aprendizado de construção de significados e saberes, com base no diálogo com o outro, se desdobra no fortalecimento da idéia de constituir uma identidade coletiva e uma legitimidade social. Essas perspectivas são percebidas nas narrativas sobre a vida e o adoecer, assim como nas novas atitudes tomadas pelas pessoas, de se solidarizarem com os sofrimentos alheios e formarem redes sociais de apoio a partir do grupo.

As narrativas se formam de modo a integrar os conhecimentos trazidos pela medicina com aspectos da cultura popular, das instituições sociais (família e religião) e das estórias individuais. Percebe-se, deste modo, a formação de um sincretismo que amplia as percepções pessoais sobre a saúde, pois permite integrar novas questões (qualidade de vida, alimentação saudável, felicidade, a solidariedade, a amizade) que transcendem uma perspectiva meramente medicalizadora da vida.

\section{Colaboradores}

Os autores Cesar Augusto Orazem Favoreto e Cristiane Coelho Cabral participaram, igualmente, de todas as etapas de elaboração do artigo.

\section{Referências}

AYRES, J.R.M. Sujeito, intersubjetividade e práticas de saúde. Cienc. Saude Colet., v.6, n.1, p.63-72, 2001.

BAKHTIN, M. Marxismo e filosofia da linguagem. 11.ed. São Paulo: Hucitec, 2004.

BROCKMEIER, J; HARRÉ, R. Narrativa: problemas e promessas de um paradigma alternativo. Psicologia: Reflex. Critica, v.16, n.3, p.525-35, 2003.

BURY, M. Illness narrative: fact or fiction? Sociol. Health Illn., v.23, n.3, p.263-85, 2001.

CAMARGO Jr, K.R. A Biomedicina. Physis, v.7, n.1, p.45-68, 1997.

CHARON, R. Narrative and medicine [perspective]. N. Engl. J. Med., v.350, n.9, p.862-4, 2004.

Narrative medicine: form, function and ethics. Ann. Intern. Med., v.134, n.1, $\overline{\text { p.83-7, }} 2001$.

DONALD, A. The words we live in. In: GREENHALGH, T.; HURWITZ, B. (Orgs.). Narrative based medicine. 3.ed. London: BMJ Books, 2002. p.17-28.

FAVORETO, C.A.O. A velha e renovada clínica dirigida à produção de um cuidado integral em saúde. In: PINHEIRO, R.; MATTOS, R. (Orgs.). Cuidado: as fronteiras da integralidade. Rio de Janeiro: Hucitec/Abrasco, 2004. p.205-20.

FRANK, A.W. The wounded storyteller. Chicago: University Chicago Press, 1995. 
GOOD, B.J.; GOOD, M.J.; DELVECCHIO, M.J. The meaning of symptoms: a cultural hermeneutics model for clinical practice. In: KLEINMAN, A.; EISENBERG, L. (Orgs.). The relevance of social science for medicine. Dordrecht: Reidel Publishing, 1981. p.165-96.

GREENHALGH, T. Narrative based medicine in a evidence based world. In:

GREENHALGH, T.; HURWITZ, B. (Orgs.). Narrative based medicine. 3.ed. London: BMJ Books, 2002. p.3-17.

HUNTER, KM. Narrative, literature, and the clinical exercise of practical reason. J. Med. Philos., n.21, p.303-20, 1996.

HYDÉN, L.C. Illness and narrative. Sociol. Health Illn., v.19, n.1, p.48-69, 1997.

KLEINMAN, A. The illness narratives: suffering, healing and the human condition. New York: Basic Books, 1988.

MELLO FILHO, J. Grupo e corpo: psicoterapia de grupo com pacientes somáticos. Porto Alegre: Artes Médicas, 2000.

SILVEIRA, L.M.C.; RIBEIRO, V.M.B. Grupo de adesão ao tratamento: espaço de "ensinagem" para profissionais de saúde e pacientes. Interface - Comunic., Saude, Educ., v.9, n.16, p.91-104, 2004.

FAVORETO, C.A.O.; CABRAL, C.C. Narraciones sobre el proceso salud-enfermedad: experiencias en grupos operativos de educación en salud. Interface - Comunic., Saúde, Educ., v.13, n.28, p.7-18, jan./mar. 2009.

La propuesta fue: analizar la ampliación de los significados en las narraciones sobre el proceso salud-enfermedad en los portadores de enfermedades crónicas que participaron de un grupo operativo de educación en salud; observar las narraciones formadas a partir de una experiencia que pretende promover la elaboración colectiva de nuevos significados para el adolecer e integrar las vivencias y saberes personales con el conocimiento biomédico y la práctica clínica. Por medio de entrevistas semi estructuradas fue avaluada la construcción de significados sobre el adolecer para más allá del modelo biomédico y los impactos sobre el modo como el paciente vivencía su proceso clínico terapéutico. Se identificó que las personas, por medio de los cambios, valorización y legitimización de significados y saberes desarrollados a partir de las vivencias individuales y colectivas en el grupo, producen cambios en sus conceptos sobre el proceso salud-enfermedad que trascienden la perspectiva medicalizadora de la biomedicina.

Palabras clave: Medicina narrativa. Educación en salud. Enfermedades crónicas. 